\title{
Acute Hepatitis E: A Rare Cause of Acute Liver Failure in a Patient With Acute Myeloid Leukemia
}

\author{
Zachary Field ${ }^{1}$, Michelle Russin ${ }^{1}$, Rodrigo M. Murillo Alvarez ${ }^{2}$, Mario Madruga ${ }^{1}$, Steve Carlan ${ }^{3}$ \\ 1. Internal Medicine, Orlando Regional Medical Center, Orlando, USA 2. Pathology, Orlando Regional Medical Center, \\ Orlando, USA 3. Obstetrics and Gynecology, Orlando Regional Medical Center, Orlando, USA
}

Corresponding author: Steve Carlan, stevecarlan@gmail.com

\begin{abstract}
Immunocompromised patients are particularly at risk to develop hepatitis E virus (HEV) infection and its related complications. We present a rare case of HEV infection in a 35-year-old Hispanic female with concomitant acute myeloid leukemia (AML). The patient presented with acute liver failure within a few weeks after receiving a blood transfusion.
\end{abstract}

Our case likely represented an acute de novo HEV infection after chemotherapy in a patient with concurrent AML, evidenced by the presence of anti-HEV IgM antibodies as well as histological findings, and with a previous history of recent transfusions being one of the strongest risk factors for transmission. Liver failure from an acute de novo hepatitis $\mathrm{E}$ infection with concurrent AML can be catastrophic in the immunosuppressed patient. Our case is particularly unique due to the uncommon presentation of acute hepatitis $\mathrm{E}$ in a non-pregnant reproductive aged Hispanic female with recently diagnosed AML. Clinicians should maintain a low threshold to test serum HEV-RNA if a patient presents with signs and symptoms suggestive of acute hepatitis.

Received 07/02/2020 Review began 07/13/2020 Review ended 09/23/2020 Published 09/24/2020

(c) Copyright 2020 Field et al. This is an open access article distributed under the terms of the Creative Commons Attribution License CC-BY 4.0., which permits unrestricted use, distribution, and reproduction in any medium, provided the original author and source are credited.
Categories: Internal Medicine, Infectious Disease, Hematology

Keywords: hepatitis e virus, liver function, acute myeloid leukemia (aml)

\section{Introduction}

Hepatitis E viral (HEV) infection has a worldwide distribution and usually has a self-limited clinical course [1-3]. In most patients, an estimated recovery occurs within four to six weeks, but immunocompromised patients are at risk of developing symptomatic acute hepatitis or even chronic infection $[4,5]$. Fecal contamination is the most common mechanism of transmission in developing countries due to poor sanitary conditions [1], while in developed countries animal reservoir transmission and transfusion-related transmission have been reported [6].

\section{Case Presentation}

A 35-year-old Hispanic female with a past medical history significant only for acute myeloid leukemia (AML), who had previously undergone chemotherapy and consolidation therapy, presented for evaluation of progressively worsening jaundice over the past seven days. She also reported clay-colored stools that developed the day prior to admission, as well as generalized symptoms of nausea, chills, and malaise. Regarding her AML, the patient was diagnosed five months prior to admission with cytogenetics revealing a $t(8 ; 21)$ translocation. She underwent induction chemotherapy with $7+3$ regimen. She then had three cycles of consolidation therapy with high-dose cytosine arabinoside. The patient was originally from Mexico, but had been living in the United States for 16 years.

The physical exam was only significant for scleral icterus and jaundice. Laboratory values are seen in Table I and were notable for an aspartate aminotransferase (AST) of 3,846 U/L (13-39 U/L), alanine aminotransferase (ALT) of 3,346 U/L (7-52 U/L), alkaline phosphatase of 189 U/L (34-104 U/L), and total bilirubin of $13.3 \mathrm{mg} / \mathrm{dL}$ [0.3-1.0 mg/dL]. An acute hepatitis panel was ordered, which tested for hepatitis A, hepatitis B, and hepatitis $\mathrm{C}$ antibodies as well as hepatitis B surface antigen, and was negative. 


\section{Cureus}

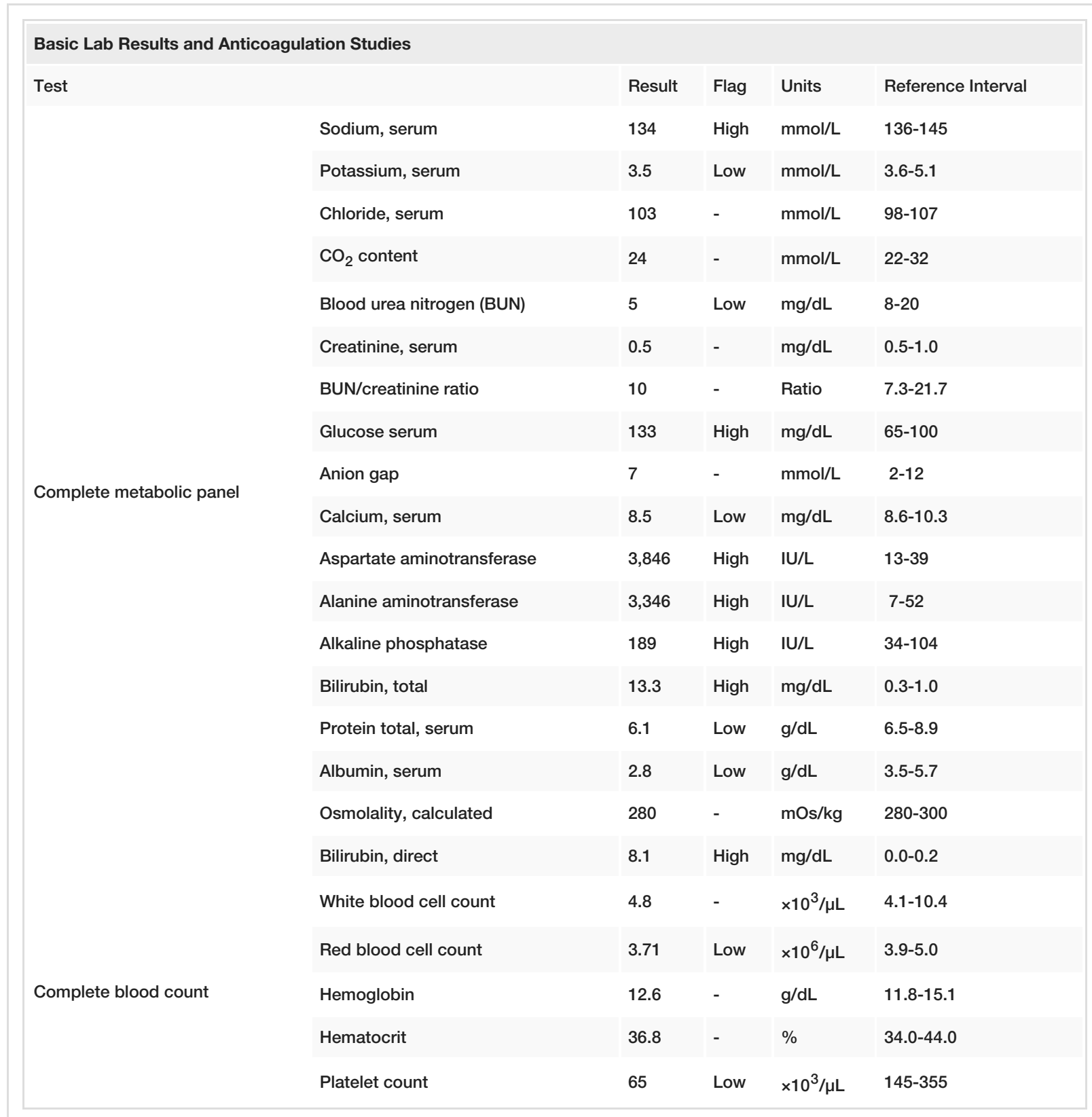

\section{TABLE 1: Laboratory values}

Her liver function tests began to improve, but the etiology of her acute liver failure remained unclear. The patient underwent magnetic resonance cholangiopancreatography (MRCP), which showed some sludge and gallstones but no pericholecystic fluid or evidence of an impacted stone (Figure 1). 


\section{Cureus}

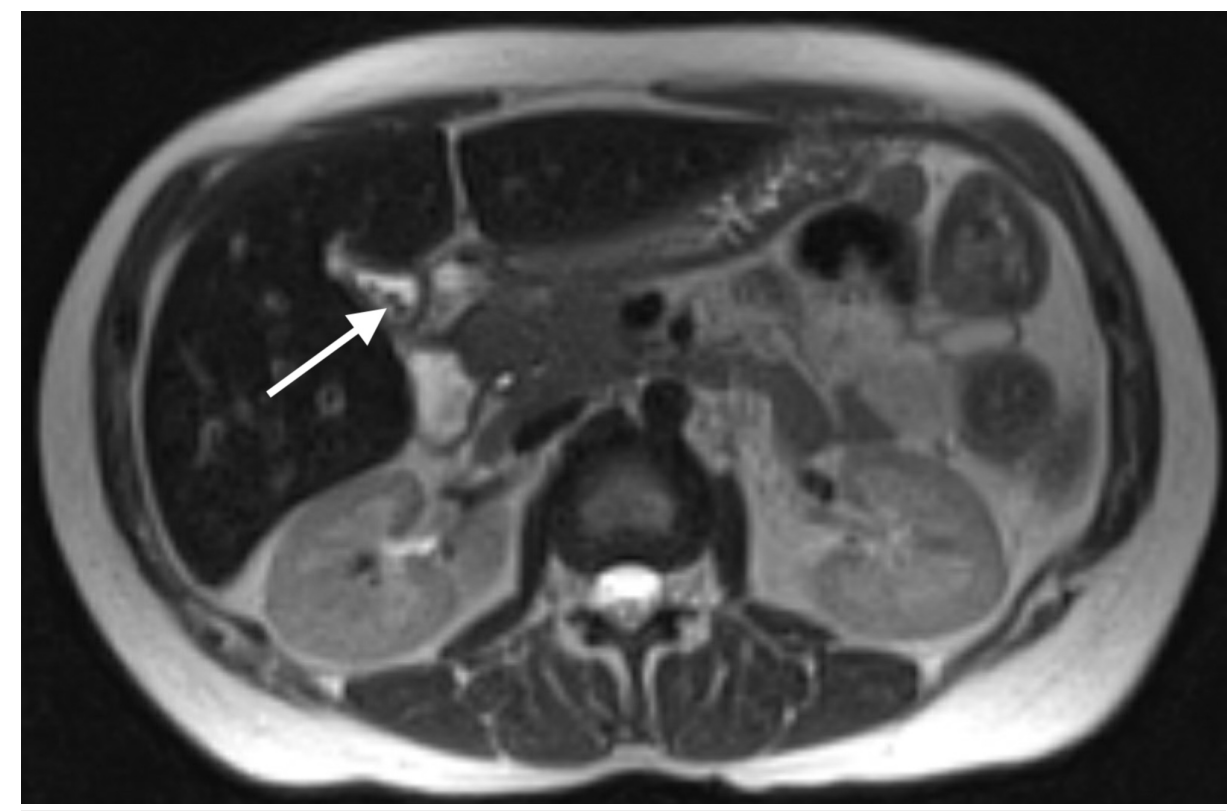

\section{FIGURE 1: Magnetic resonance cholangiopancreatography (MRCP)}

Stones (marked with arrow) and sludge within a contracted gallbladder. Gallbladder wall measuring $3 \mathrm{~mm}$, the upper limit of normal. Diffuse signal changes of the liver consistent with iron overload. No focal liver lesions are seen.

Further workup including antinuclear antibody (ANA), anti-mitochondrial antibody, anti-smooth muscle antibody, HIV antigen, acetaminophen level, ceruloplasmin level, as well as cytomegalovirus polymerase chain reaction (PCR), Epstein-Barr antibodies, herpes-simplex PCR, and hemochromatosis gene (HFE) gene analysis were all negative or within normal limits.

Iron studies were ordered that revealed a ferritin of $88 \mathrm{ng} / \mathrm{mL}(10.0-291.0 \mathrm{ng} / \mathrm{mL})$, serum iron of $240 \mu \mathrm{g} / \mathrm{dL}$ (28-170 $\mu \mathrm{g} / \mathrm{dL})$, total iron-binding capacity of $209 \mu \mathrm{g} / \mathrm{dL}(255-450 \mu \mathrm{g} / \mathrm{dL})$, transferrin saturation of $115 \%$ (20\%-50\%), and transferrin of $149 \mathrm{mg} / \mathrm{dL}$ (192-382 mg/dL). The hematology and oncology service was consulted and did not believe that her presentation was related to chemotherapy toxicity. Gastroenterology was consulted who recommended that the patient undergo a liver biopsy, which showed extensive ballooning degeneration with lobular disarray and evidence of necrosis (Figure 2).

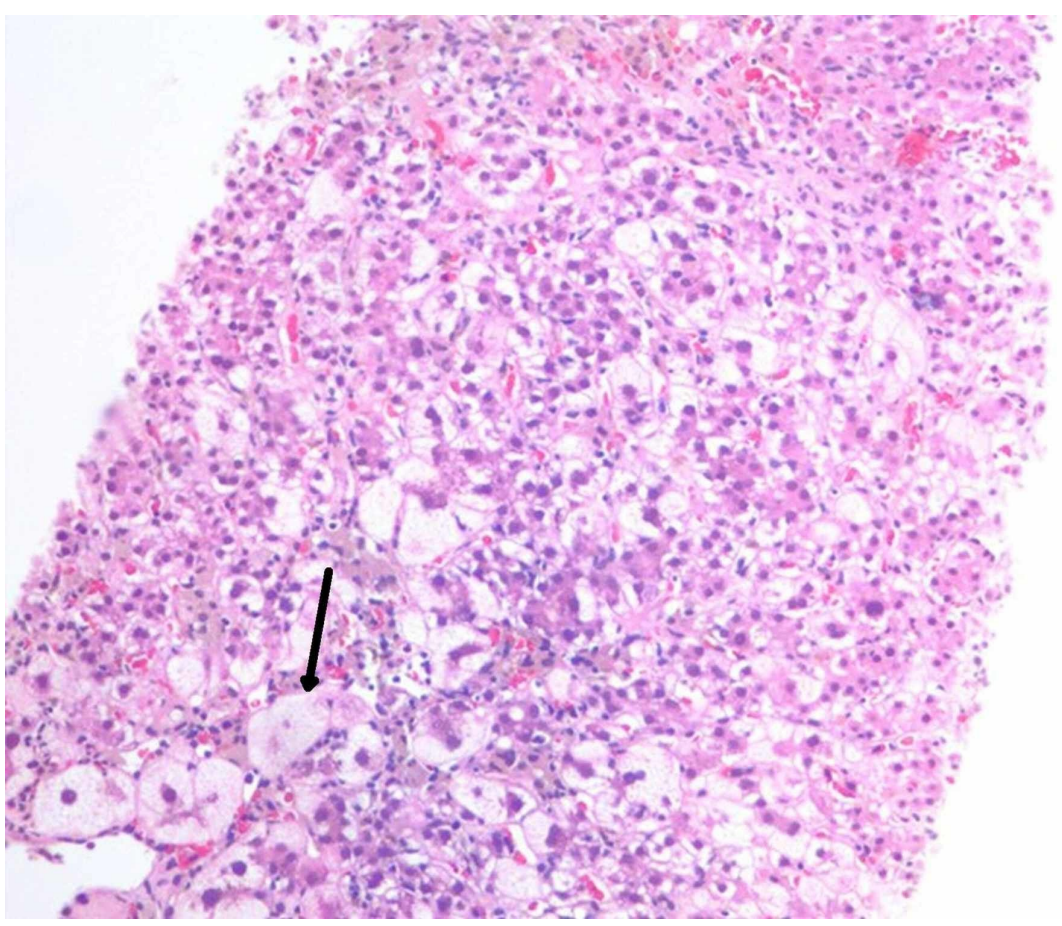


FIGURE 2: Core needle biopsy of the liver

Extensive ballooning degeneration (arrow) with lobular disarray and individual hepatocellular necrosis.

Additional stains including trichrome and reticulin stains were used to rule out increased fibrosis.

On the seventh day of hospitalization, laboratory results for HEV immunoglobulin M (IgM) antibodies were reported positive. Upon further questioning, the patient stated that she was from León, Guanajuato, located in central Mexico. She denied any prior exposure to swine or other farm animals, drinking from contaminated water sources, or consuming liver. She did state that she had received approximately 10-15 units of packed red blood cells over the past five months prior to her admission for severe anemia. Her low hemoglobin was the initial laboratory abnormality requiring workup that lead to her diagnosis of AML. Her most recent blood transfusion occurred 16 days prior to her development of jaundice.

When her symptoms and laboratory values continued improving, she was discharged from the hospital with close follow-up by hematology, oncology, and gastroenterology. She had serial comprehensive metabolic panels over the following weeks to monitor her liver function. Her ALT and AST eventually returned completely to her baseline three weeks after discharge.

\section{Discussion}

HEV is a major cause of viral hepatitis worldwide and is especially endemic in many parts of the developing world. However, hepatitis E is becoming increasingly recognized in the developed world, particularly through zoonotic transmission of genotype 3 in the United States [7]. Groups typically at high risk in developed countries are males over the age of 50 years [7,8]. Acute infection typically causes a self-limiting hepatitis that may progress to fulminant hepatitis in pregnant women [8]. More recently, rare cases of acute hepatitis with progression to chronic infection and cirrhosis have been demonstrated in immunocompromised patients [9]. Cases in patients with solid organ transplants, HIV infections, and with hematologic malignancies have been reported [10]. In industrialized countries, these infections are almost exclusively caused by genotype 3 in the immunosuppressed population [7]. Therefore, acute hepatitis E infection should be considered in patients presenting with symptomatic liver failure or abnormal liver function tests, especially with a background of malignancy, even without travel to endemic regions.

Our case is particularly unique due to the uncommon presentation of acute hepatitis $\mathrm{E}$ in a non-pregnant reproductive aged Hispanic female with recently diagnosed AML. This likely represents an acute de novo infection evidenced by the presence of IgM anti-HEV as well as histological findings of focal necrosis, ballooned hepatocytes, and acidophilic degeneration of hepatocytes. Approximately $90 \%$ of patients will test positive for IgM anti-HEV at two weeks after infection and will remain positive for up to five months later, indicating our patient was recently infected [7]. Recent studies have suggested that active hepatitis E infections in patients on immunosuppressive therapy regimens, including stem cell transplants or chemotherapy, are typically acquired de novo and do not represent reactivation of latent hepatitis $\mathrm{E}[10,11]$. There are few reports documenting the burden of hepatitis $\mathrm{E}$ in patients with hematologic malignancies but noted it may be associated with serious complications in the immunosuppressed population such as liver failure and mortality [12]. One case-controlled study found that the seroprevalence of immunoglobulin G (IgG) and IgM antibodies to HEV were found to be significantly higher in cancer patients than in controls ( $26.0 \%$ vs. $13.0 \%$; p 0.001). However, no studies to date have systematically assessed the exact prevalence or incidence of HEV co-infection among hematological patients [1]. Among the limited number of literature reports in cancer patients, it has usually been documented as chronic HEV infections, as opposed to the acute diagnosis in our patient case. Of these cases previously reported in the literature, they include a patient with untreated hairy cell leukemia, a patient with idiopathic cluster of differentiation 4 (CD4) thymus cell (T cell) lymphopenia, and patients treated for lymphoma, chronic myelomonocytic leukemia, and bursa of Fabricius cell (B cell) chronic lymphocytic leukemia [8]. To the best of our knowledge, however, there have been no reported cases of patients with AML who had previously undergone chemotherapy presenting with an acute hepatitis E infection in the United States, such as our patient.

Due to the recently discovered rising number of hepatitis E cases in immunocompromised patients, clinicians should maintain a low threshold to test serum HEV-RNA if a patient presents with signs and symptoms suggestive of acute hepatitis. Cancer patients are a high-risk population who should be informed to avoid exposure to sources of HEV infection, such as raw or undercooked foods and animal exposure [1]. In the event of HEV infection, reduction of immunosuppression has been reported successful as treatment but if not feasible or unsuccessful, ribavirin should be prescribed $[8,9,12]$. While clearance is usually spontaneous in immune-competent individuals, these at-risk groups may develop a more complicated and protracted disease course. The hepatic damage produced by the HEV can result in the production and regeneration of growth factors and may evolve into cirrhosis, putting a patient at further risk for hepatocellular carcinoma, especially in an immunosuppressed patient [1]. 
The incubation period for HEV is two to six weeks [8]. Given that our patient's symptoms developed 16 days after her last transfusion and she lacked other risk factors for contracting HEV, it is likely that she acquired the infection through a contaminated blood product transfusion. Blood product donors are not currently screened for HEV, yet there are increasing numbers of reported transmissions of acute and chronic infections in blood transfusion recipients. While knowing immunosuppressed patients are already at higher risk for acquiring viral infections, clinicians should be aware that the administration of transfused blood products may further increase the risk of HEV. Infection with HEV during the immunocompromised state can significantly alter the patient's disease course [12]. Close follow-up with any immunocompromised patient for either spontaneous viral clearance or resolution of symptoms to determine the need for therapeutic intervention is therefore recommended.

\section{Conclusions}

Although the majority of HEV infections occur in developing countries, cases in the developed world do occur and several cases have been well documented, particularly in immunocompromised hosts unable to effectively clear the infection. In this group, a high index of suspicion of HEV infection is important, especially when clinical manifestations of acute hepatitis, abnormal liver function studies, or a medical history of a hematological malignancy is present. The diagnosis is usually achieved by the identification of HEV antibodies or HEV-RNA; however, a liver biopsy can be justified in order to assess severity and evolution of the disease and to rule out other causes. A close follow-up is required to determine the need for additional interventions until the infection is entirely cleared.

\section{Additional Information}

\section{Disclosures}

Human subjects: Consent was obtained by all participants in this study. IRB Orlando Regional Health issued approval Not Applicable. IRB considers case reports such as this submission 'Not Research'. Conflicts of interest: In compliance with the ICMJE uniform disclosure form, all authors declare the following: Payment/services info: All authors have declared that no financial support was received from any organization for the submitted work. Financial relationships: All authors have declared that they have no financial relationships at present or within the previous three years with any organizations that might have an interest in the submitted work. Other relationships: All authors have declared that there are no other relationships or activities that could appear to have influenced the submitted work.

\section{References}

1. Bai M-J, Zhou N, Dong W, Li G-X, Cong W, Zhu X-Q: Seroprevalence and risk factors of hepatitis E virus infection in cancer patients in eastern China. Int J Infect Dis . 2018, 71:42-47. 10.1016/j.ijid.2018.04.003

2. Haboubi HNY, Diyar R, Benton A, Ch'Ng CL: A case of acute hepatitis E infection in a patient with nonHodgkin lymphoma treated successfully with ribavirin. Case Rep Gastrointest Med. 2017, 2017:8941218. $10.1155 / 2017 / 8941218$

3. Geng Y, Zhang H, Huang W, Harrison TJ, Geng K, Li Z, Wang Y: Persistent hepatitis E virus genotype 4 infection in a child with acute lymphoblastic leukemia. Hepat Mon. 2014, 14:e15618. 10.5812/hepatmon.15618

4. Alnuaimi K, Lavolé J, Lascoux-Combes C, Roque Afonso A-M, Sogni P, Pol S. Mallet V: Chronic hepatitis E in patients with indolent lymphoma after treatment with rituximab and bendamustine. Hepatology. 2018, 67:2468-2470. 10.1002/hep.29697

5. Nicolini L, Zappulo E, Viscoli C, Mikulska M: Management of chronic viral hepatitis in the hematological patient,. Expert Rev Anti Infect Ther. 2018, 16:227-241. 10.1080/14787210.2018.1438264

6. Fuse K, Matsuyama Y, Moriyama M, et al.: Late onset post-transfusion hepatitis E developing during chemotherapy for acute promyelocytic leukemia. Intern Med. 2015, 54:657-661. 10.2169/internalmedicine.54.2332

7. Khuroo MS, Khuroo MS, Khuroo NS: Hepatitis E: discovery, global impact, control and cure. World J Gastroenterol. 2016, 22:7030-7045. 10.3748/wig.v22.i31.7030

8. Kamar N, Dalton HR, Abravanel F, Izopet J: Hepatitis E virus infection. Clin Microbiol Rev. 2014, 27:116138. 10.1128/CMR.00057-13

9. Horvatits T, Zur Wiesch JS, Lütgehetmann M, Lohse AW, Pischke S: The clinical perspective on hepatitis E . Viruses. 2019, 11:617-636. 10.3390/v11070617

10. Abravanel F, Mansuy J-M, Huynh A, et al.: Low risk of hepatitis E virus reactivation after haematopoietic stem cell transplantation. J Clin Virol. 2012, 54:152-155. 10.1016/j.jcv.2012.02.015

11. Von Felden J, Alric L, Pischke S, et al.: The burden of hepatitis E among patients with haematological malignancies: a retrospective European cohort study. J Hepatol. 2019, 71:465-472. 10.1016/j.jhep.2019.04.022

12. Dalton HR, Saunders M, Woolson KL: Hepatitis E virus in developed countries: one of the most successful zoonotic viral diseases in human history?. J Virus Erad. 2015, 1:23-29. 